This item was submitted to Loughborough's Research Repository by the author.

Items in Figshare are protected by copyright, with all rights reserved, unless otherwise indicated.

\title{
Association between psychological distress and mortality: individual participant pooled analysis of 10 prospective cohort studies
}

\section{PLEASE CITE THE PUBLISHED VERSION}

http://dx.doi.org/10.1136/bmj.e4933

\section{PUBLISHER}

(C) The Authors. Published by the BMJ Publishing Group

\section{VERSION}

VoR (Version of Record)

\section{PUBLISHER STATEMENT}

This work is made available according to the conditions of the Creative Commons Attribution 2.0 Unported (CC BY 3.0) licence. Full details of this licence are available at: http://creativecommons.org/licenses/by/2.0/

\section{LICENCE}

CC BY-NC-ND 4.0

\section{REPOSITORY RECORD}

Russ, Tom C., Emmanuel Stamatakis, Mark Hamer, John M. Starr, Mika Kivimaki, and G. David Batty. 2019. "Association Between Psychological Distress and Mortality: Individual Participant Pooled Analysis of 10 Prospective Cohort Studies". figshare. https://hdl.handle.net/2134/19198. 


\title{
Association between psychological distress and mortality: individual participant pooled analysis of 10 prospective cohort studies
}

\author{
(c) (1) (9) OPEN ACCESS
}

\begin{abstract}
Tom C Russ alzheimer scotland clinical research fellow ${ }^{123}$, Emmanuel Stamatakis senior research associate and national institute for health research career development fellow ${ }^{4}$, Mark Hamer principal research associate ${ }^{4}$, John M Starr professor of health and ageing ${ }^{1235}$, Mika Kivimäki professor of social epidemiology ${ }^{4}$, G David Batty reader in epidemiology/wellcome trust fellow ${ }^{34}$
\end{abstract}

${ }^{1}$ Scottish Dementia Clinical Research Network, NHS Scotland, Murray Royal Hospital, Perth, UK; ${ }^{2}$ Alzheimer Scotland Dementia Research Centre, University of Edinburgh, Edinburgh EH8 9JZ, UK; ${ }^{3}$ Centre for Cognitive Ageing and Cognitive Epidemiology, University of Edinburgh $;{ }^{4}$ Department of Epidemiology and Public Health, University College London, London, UK; ${ }^{5} \mathrm{NHS}$ Lothian, Edinburgh

\begin{abstract}
Objective To quantify the link between lower, subclinically symptomatic levels of psychological distress and cause-specific mortality in a large scale, population based study.

Design Individual participant meta-analysis of 10 large prospective cohort studies from the Health Survey for England. Baseline psychological distress measured by the 12 item General Health Questionnaire score, and mortality from death certification.

Participants 68222 people from general population samples of adults aged 35 years and over, free of cardiovascular disease and cancer, and living in private households in England at study baseline.

Main outcome measures Death from all causes $(n=8365)$, cardiovascular disease including cerebrovascular disease $(n=3382)$, all cancers $(n=2552)$, and deaths from external causes $(n=386)$. Mean follow-up was 8.2 years (standard deviation 3.5).

Results We found a dose-response association between psychological distress across the full range of severity and an increased risk of mortality (age and sex adjusted hazard ratio for General Health Questionnaire scores of $1-3 v$ score $0: 1.20,95 \%$ confidence interval 1.13 to 1.27 ; scores 4-6: 1.43, 1.31 to 1.56; and scores 7-12: 1.94, 1.66 to 2.26; $\mathrm{P}<0.001$ for trend). This association remained after adjustment for somatic comorbidity plus behavioural and socioeconomic factors. A similar association was found for cardiovascular disease deaths and deaths from external causes. Cancer death was only associated with psychological distress at higher levels.
\end{abstract}

Conclusions Psychological distress is associated with increased risk of mortality from several major causes in a dose-response pattern. Risk of mortality was raised even at lower levels of distress.

\section{Introduction}

A series of studies have shown an association between symptoms of depression and anxiety (commonly referred to as psychological distress) and an elevated risk of premature mortality, ${ }^{12}$ cardiovascular disease, ${ }^{3-6}$ and potentially all cancers, ${ }^{7}$ although these are not universal observations. ${ }^{8} 9$ Prospective studies investigating these associations have generally been small in scale, with only two studies reporting more than 1000 disease events. ${ }^{10}{ }^{11}$ Smaller studies lead to unreliable estimates of risk, do not permit detailed investigation of the effect of reverse causality, and hamper insights into the association across the full range of psychological distress severity. Investigation of the role of reverse causality - the possibility that the early stages of disease (for example, chest pain) might cause psychological distress-requires large numbers of participants and events to have a sufficiently large sample after individuals with existing illness or deaths in the early phases of follow-up are excluded.

Furthermore, extant studies have been unable to adequately examine whether a dose-response association exists between distress and mortality. The increased mortality associated with mental illness that is sufficiently severe to need admission to a psychiatric hospital is well described. ${ }^{12}$ However, if the influence of psychological distress on mortality is occurring at levels 
lower that hitherto suggested-in people who would not come to the attention of mental health practitioners - this may have potentially important implications for treatment.

In view of these limitations of existing studies, we undertook an individual participant meta-analysis of 10 large, community based cohort studies of the role of psychological distress as a risk factor for death from all causes, cardiovascular disease, cancer, and external causes. In contrast to a literature based meta-analysis, which may have to exclude studies not reporting their results in an appropriate manner, the possibility of publication bias is minimised in an individual participant meta-analysis through close collaboration with data providers. Furthermore, a literature based meta-analysis cannot provide precise estimates of associations between risk markers and disease, reliable information on the shape of a specific risk factor-disease relation (for example, dose-response $v$ threshold), or a consistent approach to statistical control for plausible covariates and subgroup analyses. While this approach has been taken for physiological risk factors for mortality previously, ${ }^{1314}$ the present study is the first such meta-analysis of psychological distress.

\section{Methods \\ Study samples}

Participants were taken from the Health Survey for England, ${ }^{15} 16$ a representative health examination study sampling people from the general population living in private households in that country. From 1994 to 2004, 11 independent, cross sectional studies with identical methodologies took place on an annual basis. Consenting study members (75 936 (89.1\%)) were linked to National Health Service mortality data up to February 2008. For this analysis, we used raw data from people aged 35 years and over from all these study years, with the exception of 1996 when psychological distress was not measured. Ethical approval was obtained from the London Research Ethics Council.

\section{Measurement of psychological distress}

During a household visit, interviewers collected information using computer-assisted personal interviewing modules. We measured psychological distress using the 12 item version of the General Health Questionnaire (GHQ-12), a widely used measure of distress in population studies. ${ }^{17}{ }^{18}$ The GHQ-12 is generally considered to be a unidimensional scale of psychological distress, ${ }^{19}$ consisting of items capturing symptoms of anxiety, depression, social dysfunction, and loss of confidence. Study members respond to whether a symptom is present by using a four point Likert scale ("not at all" $=0$, "same as usual"=0, "more than usual"=1, "much more than usual"=1). A total GHQ-12 score of four or greater leads to people being defined as psychological distress "cases" and scores 0-3 as "non-cases"; this definition has been validated against standardised psychiatric interviews and has been strongly associated with various psychological disorders such as depression and anxiety. ${ }^{20}{ }^{21}$ Most previous studies used such a dichotomy and few have examined associations across the full range of psychological distress. No standard cut-off values exist for dividing up "cases" identified by a GHQ-12 score threshold. We therefore chose to divide people into four groups based on their GHQ-12 score: asymptomatic (score 0), subclinically symptomatic (score 1-3), symptomatic (score 4-6), and highly symptomatic (score 7-12).

\section{Mortality data}

Causes of death recorded on death certificates were coded using the international classification of diseases, 9 th and 10 th revisions (ICD-9 and ICD-10, respectively). We identified cardiovascular disease deaths (including ischaemic heart disease,

cerebrovascular disease, peripheral vascular disease and heart failure) using codes 410-414, 430-438, 440, 443-5, and 428 (ICD-9); and I20-I25, I50, I60-70, I73 and I74 (ICD-10). Cancer deaths were identified using codes 140-239 (ICD-9) and C00-D48 (ICD-10). We identified deaths from external causes using codes 800-999 and E800-E999 (ICD-9) and S00-Y98 (ICD-10). For the main analyses, any mention of a condition on the death certificate was counted but a subgroup analysis restricted cases to those where the condition was the underlying cause of death.

\section{Statistical analyses}

We ascertained that the proportional hazards assumption had not been violated by inspecting the $\log (-\log ($ survival $))$ plot. We then used Cox proportional hazards models ${ }^{22}$ to compute study-specific hazard ratios with accompanying $95 \%$ confidence intervals for the association of GHQ-12 score with mortality outcomes. Heterogeneity in the effect estimates between studies was examined using the $\mathrm{I}^{2}$ statistic, which indicates the proportion of the total variation in the estimates due to between-studies variation. The $\mathrm{I}^{2}$ varied between $0 \%$ and $81.1 \%$, depending on the mortality outcome and psychological distress variable used in the analysis. Owing to this heterogeneity, we pooled the study-specific effect estimates and their standard errors in random effects meta-analyses. Study members scoring 0 on the GHQ-12 were regarded as being free of psychological distress and used as the reference group. We compared this group with the three GHQ-12 score groups (scores 1-3, 4-6, and 7-12), and also reported the hazard ratio per one standard deviation increment in GHQ-12 score (calculated with sex specific standard deviations: men 2.41, women 2.75).

Days were the time scale and, for participants with no record of an event, the data were censored at 15 February 2008. Models were adjusted for age (years), sex, current occupational social class (professional, managerial or technical, skilled non-manual, skilled manual, partly skilled, and unskilled), body mass index, systolic blood pressure (mm $\mathrm{Hg}$ ), physical activity (any moderate to vigorous physical activity in a week), smoking status (not a current smoker; or <5, 5-10, 10-15, 15-20, and >20 cigarettes per day), alcohol consumption (units per week), and diabetes at baseline (yes or no). Details on the measurement protocols and data handling of these covariates can be found elsewhere. ${ }^{16}{ }^{23}$ We calculated the population proportional attributable risk for each mortality outcome and the four categories of GHQ-12 score using a standard equation. ${ }^{24}$ To further examine the association between crude GHQ-12 score and mortality (all cause, cardiovascular disease, cancer, and external causes), we meta-analysed study specific Cox proportional hazard models to calculate age and sex adjusted hazard ratios and 95\% confidence intervals for each GHQ-12 score, with score 0 as the reference. In addition, we did a subgroup analysis to investigate potential reverse causality; analyses were repeated dropping deaths within the first five years of follow-up. This analysis did not include deaths from external causes.

We compared people with data missing for one or more variable with those with complete data. Covariates were compared with Student's $t$ test for continuous variables and $\chi^{2}$ tests for categorical variables. In the sensitivity analysis, we imputed 
missing values for covariates with Predictive Analytics Software version $18.0,{ }^{25}$ using five imputations. All other analyses were conducted using $\mathrm{R}$ version $2.15 .0^{26}$ and the survival and metafor ${ }^{27}$ packages. Figures were constructed using the Rmeta ${ }^{28}$ and gplots packages. The reporting of this study conforms to the STROBE statement. $^{29}$

\section{Results}

The initial pooled sample included 85261 adults. Table $1 \Downarrow$ shows details of individual studies. We excluded participants who declined linkage to mortality records $(n=9325$; web table 1 compares those who consented to record linkage with those who did not); with missing GHQ-12 data $(n=2532)$; with baseline cardiovascular disease $(n=3492)$, cancer $(n=1511)$, or both ( $\mathrm{n}=159)$; and with no cause of death recorded or for whom no survival time could be calculated $(\mathrm{n}=20)$. The final analytic sample comprised 68222 people (37 649 (55.2\%) women) with a mean age of 55.1 years (standard deviation 14.1, range 35-102). The composition of the sample is shown in figure $1 \Downarrow$. Table $2 \Downarrow$ shows details of the study members' baseline characteristics. People with higher GHQ-12 scores generally had unfavourable levels of covariates and mortality risk, apart from being slightly younger and having a lower systolic blood pressure than those with lower GHQ-12 scores. Participants with the highest GHQ-12 scores were slightly less likely to drink heavily than those with lower scores.

Of 8365 deaths during a mean follow-up of 8.2 years (standard deviation 3.5), 3382 death certificates mentioned cardiovascular disease, 2552 mentioned cancer, and 386 mentioned an external cause of death. Figure $2 \Downarrow$ shows the numbers of participants, total deaths, and the number related to major causes of death. It also provides the age and sex adjusted hazard ratio for the relation of increased psychological distress (one standard deviation increase in GHQ-12 score) with overall mortality, cardiovascular disease death, cancer death, and death from external causes for each annual cohort in addition to the totals and overall effect from meta-analysis. Overall, we saw increases of $21 \%$ in age and sex adjusted risk of all cause mortality, $22 \%$ in risk of cardiovascular disease death, $9 \%$ in risk of cancer death, and $26 \%$ in risk of death from external causes per standard deviation increase in GHQ-12 score. Individually, all cohorts showed a similar effect, although the strength of the association between GHQ-12 score and mortality was somewhat weaker for 1997 and 2002 - the reason for this is unclear. However, when we conducted sensitivity analyses by excluding the 1997 and 2002 cohorts from pooled analyses, the hazard ratio was unchanged. Therefore, we included participants from these surveys in the main analyses.

\section{Deaths from all causes}

We saw a significant association, across the full range of severity, between psychological distress and all cause mortality. Table $3 \Downarrow$ shows the results for the four categories of GHQ-12 score; even the subclinically symptomatic group (score 1-3) had a 20\% increased risk of mortality after adjusting for age and sex. This association was essentially unchanged after adjusting for a range of covariates that included occupational social class, alcohol intake, and smoking. We saw strong evidence of a dose-response effect (age and sex adjusted hazard ratio per standard deviation disadvantage in GHQ-12 score 1.21, 95\% confidence interval 1.15 to $1.27 ; \mathrm{P}<0.001$ for trend). Figure $3 \Downarrow$ shows the association between risk of death from all causes and the full range of psychological distress.

\section{Cardiovascular disease death}

Focusing on cardiovascular disease death in particular showed a similarly increased risk in association with psychological distress, again across the full range of severity; subclinically symptomatic patients were at a $29 \%$ increased risk of cardiovascular disease death (table 3 ). This association remained after adjustment for each covariate individually and in a model incorporating all covariates. The magnitude of the increase in risk in the fully adjusted model was little attenuated. Again, there was strong evidence of a dose-response effect (age and sex adjusted hazard ratio per standard deviation disadvantage in GHQ-12 score $1.22,95 \%$ confidence interval 1.14 to 1.31 ; $\mathrm{P}<0.001$ for trend) across the full range of GHQ-12 scores (fig 3).

\section{Cancer deaths}

Cancer death was not associated with low levels of psychological distress in the same way as cardiovascular disease death (table 3). However, psychological distress in highly symptomatic patients (GHQ-12 scores 6-12) was associated with a $41 \%$ increased risk of cancer death. Figure 3 confirms that this association was only present in GHQ-12 scores greater than six. Nevertheless, we saw a significant dose-response effect (age and sex adjusted hazard ratio per standard deviation disadvantage in GHQ-12 score 1.09, 95\% confidence interval 1.04 to $1.13 ; \mathrm{P}<0.001$ for trend). This association remained after adjustment for all covariates individually and in the fully adjusted model (hazard ratio per standard deviation disadvantage in GHQ-12 score $1.05,0.99$ to $1.11, \mathrm{P}=0.141$ ).

\section{Deaths from external causes}

Death from external causes was also associated with psychological distress across the full range of scores; subclinically symptomatic patients were at a $29 \%$ increased risk of death from external causes (table 3 ). This association remained on adjustment for covariates individually and remained unchanged in the fully adjusted model. Once again, we saw strong evidence of a dose-response effect (age and sex adjusted hazard ratio per standard deviation disadvantage in GHQ-12 score $1.26,95 \%$ confidence interval 1.14 to 1.40 ; $\mathrm{P}<0.001$ for trend) across the full range of GHQ-12 scores (fig 3).

The population proportional attributable risk summarises the population effect of an exposure taking into account its prevalence. For the subclinically symptomatic category of psychological distress, the proportional attributable risk was $3.8 \%$ for overall mortality (fully adjusted hazard ratio 1.16 ), $5.8 \%$ for cardiovascular disease mortality $(1.25),-1.2 \%$ for cancer mortality (0.95), and $5.4 \%$ for deaths from external causes (1.23).

\section{Sensitivity analysis}

Data were missing for one or more variables in $39.4 \%(n=26$ $860)$ of the sample. People with missing data were older and were more likely to be female, be overweight, have lower blood pressure, be less active, not smoke, drink alcohol within recommended limits, and have diabetes at baseline. However, they were no more likely to belong to a non-manual occupational social class (web table 2). Therefore, participants with missing data did not always have unfavourable levels of risk factors. Accounting for missing data by multiple imputation did not alter the effect sizes found (table $4 \Downarrow$ ). 


\section{Subgroup analyses}

We excluded deaths occurring within the first five years of follow-up to examine reverse causality. This subgroup analysis slightly attenuated the effect size for the association between psychological distress and all cause mortality (age and sex adjusted hazard ratio per standard deviation disadvantage in GHQ-12 score [all data] $1.21,95 \%$ confidence interval 1.15 to $1.27, \mathrm{P}<0.001 v 1.13,1.10$ to $1.17, \mathrm{P}<0.001)$ and cardiovascular disease death (web table 3 ). The association with cancer deaths was further attenuated towards the null by excluding deaths within the first five years of follow-up (web table 3 ). Comparing a narrow case definition (that the condition was the underlying cause of death) and a broad case definition (that any mention of the condition on the death certificate was sufficient) had essentially no effect on the results (web table 4).

\section{Discussion}

The main finding of this study was a dose-response association between psychological distress and mortality from all causes, cardiovascular disease, and external causes across the full range of distress, even in people who would not usually come to the attention of mental health services. A similar association with cancer was only seen at higher levels of psychological distress. These associations remained after adjustment for age, sex, current occupational social class, body mass index, systolic blood pressure, physical activity, smoking, alcohol consumption, and diabetes. The associations with deaths from all causes, cardiovascular disease, and cancer remained after deaths in the first five years of follow-up were excluded.

\section{Study strengths and limitations}

This study is the first to use an individual participant meta-analysis methodology to examine the association between a psychological variable and mortality. It used a very large sample of the general population, and over 8000 participants died during follow-up. This large sample size provides sufficient power to allow detailed analyses to be conducted and reverse causality to be investigated. The cohort participants were well characterised, allowing relevant contextual variables to be incorporated into the statistical models, although the possibility of residual confounding remains.

Using GHQ-12 score to estimate psychological distress, although widely used in population based studies ${ }^{18}$ is not without limitations. The scale itself, with non-specific questions about feelings of unhappiness and confidence, worry, and feelings of worthlessness, does not provide a clinical diagnosis of anxiety or depression, even though the 12 items do capture several diagnostic criteria in ICD-10 or the Diagnostic and Statistical Manual of Mental Disorders, fourth edition. However, there is evidence that screening positive on the GHQ-12, defined here as scores of 4 or more, is associated with anxiety and depression. ${ }^{20} \mathrm{GHQ}-12$ has been shown to be a valid screening tool for anxiety and depression diagnosed according to the Diagnostic and Statistical Manual of Mental Disorders, third edition (revised)..$^{30}$

Classifying cause of death according to death certification is a common methodology in epidemiological studies. Since causes of death are based on the certifying doctor's clinical assessment and knowledge of the deceased person, they may not always be perfectly accurate, but it is likely that the broad causes of death (for example, cardiovascular disease and cancer) used in the present study were sufficiently valid. The only study in the United Kingdom comparing death certification, with about 60 autopsy findings, ${ }^{31}$ found that cardiac disease was correctly recorded on death certificates in all 21 cases and neoplastic disease was correctly recorded in 14 of 18 cases. Elsewhere, in Norway, analyses of 1140 autopsies showed that death certification of stroke and ischaemic heart disease was satisfactory for the purposes of epidemiological research. ${ }^{32}$

Another limitation in the current study was the relatively large number of participants with data missing for one or more variables. The differences between those with and without missing data, detailed above, were all highly significant, apart from current occupational social class. However, statistical significance was partly achieved as a result of the large sample size and the absolute differences are small and unlikely to be clinically significant. People with missing data were not always at an increased risk of mortality. Indeed, the sensitivity analysis using multiple multivariate imputation techniques did not alter the effect sizes reported; thus, bias resulting from the missing data was unlikely.

The diminishing magnitude of association between psychological distress and mortality with increasing duration of follow-up shown in figure 2 may reflect reverse causality. That is, undiagnosed somatic illness will be associated with both an increased prevalence of psychological distress and an increased risk of mortality. The effect of hidden somatic illness will diminish with increasing duration of follow-up as people with such conditions die, potentially resulting in the trend seen in figure 2. One specific criticism of many prospective studies considering depression as a causal factor in cardiovascular disease is that subclinical atherosclerosis is not controlled for, ${ }^{33}$ and persistent depressive symptoms have been shown to be associated with coronary atherosclerosis. ${ }^{34}$ While the current study did not have any direct measures of atherosclerosis, we excluded patients with overt cardiovascular disease at baseline and further exclusion of deaths within five years of follow-up reduced the possibility that our findings were driven by subclinical disease.

\section{Comparison with other studies}

One study of 4501 adults in primary care reported a dose-response association between psychological distress (measured by the GHQ-12) and overall mortality (366 deaths; GHQ-12 score 1-3: hazard ratio $1.38,95 \%$ confidence interval 1.06 to 1.79 ; score $4-12: 1.71,1.32$ to 2.23 ), mainly due to ischaemic heart disease and respiratory diseases. ${ }^{2}$ A smaller study $(n=923)$ found a $16 \%$ increase in mortality per point increase in GHQ-12 score, mainly in men (hazard ratio 1.16, 1.07 to $1.25, \mathrm{P}<0.001) .{ }^{35}$ The Framingham Heart Study found a direct association between depressive symptoms and all cause mortality in 3634 people (hazard ratio per tertile increment on the Center for Epidemiologic Studies depression scale 1.37, $95 \%$ confidence interval 1.10 to $1.71 ; \mathrm{P}=0.005$ for trend). ${ }^{36} \mathrm{In}$ the Whitehall II study of 10000 British civil servants, psychological distress, measured by a 30 item GHQ scale, was not associated with death from all cause mortality ( 355 deaths). ${ }^{37}$ Therefore, the present study is the largest so far to show a dose-response relation between psychological distress and mortality.

The association between depression and mortality is less clear in later life, but the association remains even with adjustment for cognitive and functional impairment and social support. However, the association seems to disappear when people are followed up over long periods. ${ }^{37-39}$ This finding is consistent with our data because the effect estimates were smallest in participants with the longest follow-up period (the earliest surveys) compared with those with shorter follow-up (more 
recent surveys; fig 2). As mentioned above, this difference might relate to dilution of the effect of undiagnosed somatic illness at baseline. Changes in psychological distress during the follow-up could have attenuated associations with mortality.

As described, prospective studies investigating the association between psychological distress and cardiovascular disease have also generally been small and therefore underpowered, none reporting more than several hundred cardiovascular events. ${ }^{2}{ }^{9}{ }^{40-42}$ However, they all found an increased risk of cardiovascular disease, one reporting a dose-response association (137 deaths from all circulatory disease; hazard ratios 1.42 and 1.66 for GHQ-12 scores 1-3 and 4-12, respectively). ${ }^{2}$ A study looking at phobic anxiety found an age adjusted relative risk of fatal coronary heart disease of $3.01(n=40) \cdot{ }^{34}$ A meta-analysis of 21 studies investigating the association between depressive symptoms and coronary heart disease incidence found a pooled relative risk of 1.81, similar for fatal and non-fatal outcomes but greater for clinically diagnosed depression than depressive symptoms. ${ }^{6}$ A recent meta-analysis showed a pooled adjusted hazard ratio of 1.45 (95\% confidence interval 1.29 to 1.63 ) for depression and stroke. ${ }^{43}$ These effect estimates are similar to most published studies investigating depression or depressive symptoms as aetiological risk factors for cardiovascular disease, which generally report a relative risk of 1.5 to 2 , though the Whitehall II study only identified an association in men. ${ }^{42}$ The results of the current study, using cardiovascular disease death as the outcome of interest, are comparable to the results of this recent meta-analysis. ${ }^{43}$

One large retrospective study found a risk ratio of 1.39 for myocardial infarction in 12304 participants with depression. ${ }^{44}$ However, the absence of data for the presence of prevalent cardiovascular disease at baseline is an important limitation, particularly by comparison with the extensive baseline assessment in the Health Survey for England.

Distress in general is sometimes dismissed as a reaction to the diagnosis of a serious physical illness. In the present study, excluding deaths in the first five years of follow-up attenuated the association between psychological distress and cancer mortality, suggesting that this might partly explain the association. However, a meta-analysis of 165 studies found an association between stress related psychological factors and cancer incidence in healthy people $(\mathrm{P}=0.005){ }^{7}$ In addition, chronic and severe depression is possibly associated with cancer incidence, with a stronger association generally found with disease progression. ${ }^{33}$

\section{Mechanism of effect}

The mechanism of the association between psychological distress and mortality might be direct or indirect. A direct effect could be a physiological change associated with an increased risk of death. For example, acute psychological stress does alter cardiovascular physiology and is associated with transient myocardial ischaemia even in the absence of disease. ${ }^{3}$ Furthermore, both psychological stress and depression could lead to dysregulation of the hypothalamic-pituitary-adrenal axis, resulting in a modest increase in inflammatory markers and cortisol release. ${ }^{45}$ Depressive symptoms are associated with altered autonomic functioning, such as 3-methoxy-phenylglycol (a major metabolite of noradrenaline) response to stressors. ${ }^{41}$ Depressive symptoms are also associated with increased levels of inflammatory markers, including $\mathrm{C}$ reactive protein, ${ }^{9}$ interleukin 6, and tumour necrosis factor $\alpha .{ }^{45}$ Antidepressant drugs have been shown to suppress the inflammatory response, ${ }^{45}$ but use of these substances has been associated with increased systemic inflammation independent of comorbidity ${ }^{46}$ and increased cardiovascular disease. ${ }^{47}$ General population surveys show that about $3.7 \%$ of patients will have taken an antidepressant during the past year. ${ }^{48}$ Therefore, it is unlikely that antidepressant use alone can explain the increased risk of mortality found with psychological distress.

Psychiatric illness is associated with increased mortality ${ }^{49}$ and part of this association could be mediated by behavioural and lifestyle factors ${ }^{50}$ including physical inactivity and smoking. However, we were able to incorporate many of the important behavioural and lifestyle factors into the models in the current study, and the association between psychological distress and mortality remained highly significant, suggesting that indirect mechanisms are unlikely to completely explain this association.

\section{Implications}

Depression is a serious and debilitating disorder requiring treatment in its own right, but the finding that any level of psychological distress is associated with increased mortality and an increased risk of death from cardiovascular disease, external causes, and cancer (albeit only at higher levels of distress) is highly important. Furthermore, only two studies, much smaller than the present study, have previously demonstrated a dose-response relation between psychological distress and all cause ${ }^{35}$ or cardiovascular disease mortality, ${ }^{2}$ with other studies having compared presence and absence of psychological distress. ${ }^{490-42}{ }^{46}$ However, due to its large sample size, the present study was able to offer detailed insight into this dose-response relation. All participants with any psychological distress, even those with low GHQ-12 scores (and therefore considered subclinically symptomatic), were at an increased risk of mortality from all causes, cardiovascular disease, and external causes. The association between psychological distress and cancer was not present in subclinically symptomatic patients. One study has identified that different aspects of distress (depression, apathy or anergia, and anxiety measured by the 30 item GHQ) have differential effects on causes of death. ${ }^{46}$

While the association between psychological distress and mortality has attracted a great deal of attention, little evidence indicates favourable effects, in terms of mortality, with treatment. Trial evidence has not suggested that treating depression decreases mortality in patients with existing cardiovascular disease, ${ }^{51-53}$ but evidence from the current study of the increased risk associated with even low levels of psychological distress in the general population suggests that the overall picture may be more complex. Further research is required to investigate whether treating psychological distress, including overt depression or different aspects of distress, could have an ameliorating effect on the increased mortality demonstrated here.

Contributors: GDB conceived and designed the study. ES, MH, and GDB were responsible for acquisition of data. TCR, MK, and GDB were responsible for analysis and interpretation of data. TCR and GDB drafted the manuscript. TCR, ES, MH, JMS, MK, and GDB critically revised the manuscript for important intellectual content. TCR, ES, MK, and GDB did the statistical analysis. GDB obtained funding. MH, MK, and GDB were responsible for study supervision. TCR and GDB are the study guarantors. All authors, external and internal, had full access to all of the data (including statistical reports and tables) in the study and can take responsibility for the integrity of the data and the accuracy of the data analysis. 


\section{What is already known on this topic}

Evidence indicates an association between symptoms of depression and anxiety (commonly referred to as psychological distress) and mortality from various major causes

However, previous studies have been underpowered and unable to reliably ascertain thresholds of risk

\section{What this study adds}

A dose-response association exists between psychological distress and major causes of mortality across the full range of distress That a considerably raised risk of mortality was evident, even at low levels of psychological distress, should prompt research into whether treatment can modify this increased risk

Competing interests: All authors have completed the Unified Competing Interest form at www.icmje.org/coi_disclosure.pdf (available on request from the corresponding author) and declare: no support from any organisation for the submitted work; no financial relationships with any organisations that might have an interest in the submitted work in the previous 3 years; no other relationships or activities that could appear to have influenced the submitted work.

Funding: The study did not receive any specific funding. TCR is supported by Alzheimer Scotland and employed in the NHS by the Scottish Dementia Clinical Research Network, which is funded by the Chief Scientist Office (part of the Scottish Government Health Directorates). TCR and JMS are members of the Alzheimer Scotland Dementia Research Centre funded by Alzheimer Scotland. TCR, JMS, and GDB are members of the University of Edinburgh Centre for Cognitive Ageing and Cognitive Epidemiology, part of the cross council Lifelong Health and Wellbeing Initiative (G0700704/84698). The Biotechnology and Biological Sciences Research Council, Engineering and Physical Sciences Research Council, Economic and Social Research Council, and United Kingdom Medical Research Council provided funding. ES is supported by a National Institute for Health Research career development fellowship. MK is supported by the UK Medical Research Council, the Academy of Finland, and the United States National Institutes of Health (R01HL036310; R01AG034454). GDB is a Wellcome Trust Fellow. All researchers are independent from the funders.

Ethical approval: Ethical approval was obtained from the London Research Ethics Council.

Data sharing: no additional data available.

1 Huppert FA, Whittington JE. Symptoms of psychological distress predict 7-year mortality Psychol Med 1995;25:1073-86.

2 Robinson KL, McBeth J, MacFarlane GJ. Psychological distress and premature mortality in the general population: a prospective study. Ann Epidemiol 2004;14:467-72.

3 Brotman DJ, Golden SH, Wittstein IS. The cardiovascular toll of stress. Lancet 2007;370:1089-100

4 Hamer M, Molloy GJ, Stamatakis E. Psychological distress as a risk factor for cardiovascular events: pathophysiological and behavioral mechanisms. J Am Coll Cardiol 2008:52:2156-62.

5 Hemingway $\mathrm{H}$, Marmot M. Psychosocial factors in the aetiology and prognosis of coronary heart disease: systematic review of prospective cohort studies. BMJ 1999;318:1460-7.

6 Nicholson A, Kuper H, Hemingway H. Depression as an aetiologic and prognostic factor in coronary heart disease: a meta-analysis of 6362 events among 146538 participants in 54 observational studies. Eur Heart J 2006;27:2763-74.

7 Chida Y, Hamer M, Wardle J, Steptoe A. Do stress-related psychosocial factors contribute to cancer incidence and survival? Nat Clin Prac Oncol 2008;5:466-75

8 Hamer M, Chida Y, Molloy GJ. Psychological distress and cancer mortality. J Psychosom Res 2009;66:255-8.

9 Rasul F, Stansfeld S, Hart C, Davey Smith G. Psychological distress, physical illness, and risk of coronary heart disease. J Epidemiol Community Health 2005;59:140-5.

10 Davis MC, Matthews KA, Twamley EW. Is life more difficult on Mars or Venus? A meta-analytic review of sex differences in major and minor life events. Ann Behav Med 1999;21:83-97.

11 Öhlin B, Nilsson P, Nilsson J, Berglund G. Chronic psychosocial stress predicts long-term cardiovascular morbidity and mortality in middle-aged men. Eur Heart J 2004:25:867-73.

12 Gale CR, Batty GD, Osborn DPJ, Tynelius P, Whitley E, Rasmussen F. Mental disorders in early adulthood and later psychiatric hospital admissions in relation to mortality in a cohort of a million men. Arch Gen Psychiatry [forthcoming].

13 Lewington S, Clarke R, Qizilbash N, Peto R, Collins R. Age-specific relevance of usual blood pressure to vascular mortality: a meta-analysis of individual data for one million adults in 61 prospective studies. Lancet 2002;360:1903-13.

14 Seshasai SRK, Kaptoge S, Thompson A, Di Angelantonio E, Gao P, Sarwar N, et al. Diabetes mellitus, fasting glucose, and risk of cause-specific death. $N$ Engl J Med 2011;364:829-41.

15 Colhoun H, Dong W, Prescott-Clarke P. Health survey for England: survey methodology and documentation. HMSO, 1994
16 Mindell J, Biddulph JP, Hirani V, Stamatakis E, Craig R, Nunn S, et al. Cohort profile: the health survey for England. Int $J$ Epidemiol 2012: published online 9 January.

17 Goldberg DP. Manual of the General Health Questionnaire. NFER, 1978.

18 Goldberg DP, Gater R, Sartorius N, Ustun T, Piccinelli M, Gureje O, et al. The validity of two versions of the GHQ in the WHO study of mental illness in general health care. Psychol Med 1997:27:191-7.

19 Hankins M. The factor structure of the twelve item General Health Questionnaire (GHQ-12): the result of negative phrasing? Clin Pract Epidemiol Ment Health 2008;4:10.

20 Holi MM, Marttunen M, Aalberg V. Comparison of the GHQ-36, the GHQ-12 and the SCL-90 as psychiatric screening instruments in the Finnish population. Nord J Psychiat 2003;57:233-8.

21 Aalto A-M, Elovainio M, Kivimaki M, Uutela A, Pirkola S. The Beck Depression Inventory and General Health Questionnaire as measures of depression in the general population: a validation study with the Composite International Diagnostic Interview as the gold standard. Psychiatry Res [forthcoming].

22 Cox DR. Regression models and life-tables. J Royal Stat Soc B 1972;34:187-220.

23 Stamatakis E, Hamer M, Primatesta P. Cardiovascular medication, physical activity and mortality: cross-sectional population study with ongoing mortality follow-up. Heart 2009;95:448-53.

24 Kirkwood B, Sterne J. Essential medical statistics . 2nd ed. Blackwell, 2003.

25 SPSS Inc. PASW statistics 18.0. SPSS Inc, 2010.

26 R Development Core Team. R: a language and environment for statistical computing . R Foundation for Statistical Computing, 2010.

27 Viechtbauer W. Conducting meta-analyses in R with the metafor package. J Stat Softw 2010;36:1-48.

28 Lumley T. Rmeta version 2.16. R package. 2009. http://cran.r-project.org.

29 Von Elm E, Altman D, Egger M, Pocock SJ, Gøtzsche PC, Vandenbroucke JP. Strengthening the reporting of observational studies in epidemiology (STROBE) statement: guidelines for reporting observational studies. BMJ 2007;335:806-8.

30 Schmitz N, Kruse J, Heckrath C, Alberti L, Tress W. Diagnosing mental disorders in primary care: the General Health Questionnaire (GHQ) and the Symptom Check List (SCL-90-R) as screening instruments. Soc Psych Psych Epid 1999;34:360-6.

31 Harris M, Blundell J. Audit of necropsies in a British district general hospital. J Clin Pathol 1991;44:862-5.

32 Gulsvik AK, Gulsvik A, Svendsen E, Mæhle BO, Thelle DS, Wyller TB. Diagnostic validity of fatal cerebral strokes and coronary deaths in mortality statistics: an autopsy study. Eur Epidemiol 2011:26:221-8.

33 Spiegel D, Giese-Davis J. Depression and cancer: mechanisms and disease progression. Biol Psychiatry 2003;54:269-82.

34 Kawachi I, Colditz GA, Ascherio A, Rimm EB, Giovannucci E, Stampfer MJ, et al. Prospective study of phobic anxiety and risk of coronary heart disease in men. Circulation 1994;89:1992-7.

35 Puustinen $\mathrm{PJ}$, Koponen $\mathrm{H}$, Kautiainen $\mathrm{H}$, Mantyselka P, Vanhala M. Psychological distress measured by the GHQ-12 and mortality: a prospective population-based study. Scand $J$ Public Health 2011;39:577-81.

36 Wulsin LR, Evans JC, Vasan RS, Murabito JM, Kelly-Hayes M, Benjamin EJ. Depressive symptoms, coronary heart disease, and overall mortality in the Framingham Heart Study. Psychosom Med 2005;67:697-702.

37 Kivimaki M, Head J, Ferrie JE, Shipley MJ, Vahtera J, Marmot MG. Sickness absence as a global measure of health: evidence from mortality in the Whitehall II prospective cohort study. BMJ 2003;327:364-8.

38 Blazer DG, Hybels CF, Pieper CF. The association of depression and mortality in elderly persons. J Gerontol A-Biol 2001;56:M505-9.

39 Penninx BWJH, Geerlings SW, Deeg DJH, van Eijk JTM, van Tilburg W, Beekman ATF. Minor and major depression and the risk of death in older persons. Arch Gen Psychiatry 1999;56:889-95.

40 May M, McCarron P, Stansfeld S, Ben-Shlomo Y, Gallacher J, Yarnell J, et al. Does psychological distress predict the risk of ischemic stroke and transient ischemic attack? The Caerphilly Study. Stroke 2002;33:7-12.

41 Molloy GJ, Stamatakis E, Randall G. Hamer M. Marital status, gender and cardiovascular mortality: behavioural, psychological distress and metabolic explanations. Soc Sci Med 2009:69:223-8.

42 Stansfeld SA, Fuhrer R, Shipley MJ, Marmot MG. Psychological distress as a risk facto for coronary heart disease in the Whitehall II Study. Int J Epidemiol 2002;31:248-55.

43 Pan A, Sun Q, Okereke OI, Rexrode KM, Hu FB. Depression and risk of stroke morbidity and mortality. JAMA 2011;306:1241-9.

44 Scherrer JF, Chrusciel T, Zeringue A, Garfield LD, Hauptman PJ, Lustman PJ, et al. Anxiety disorders increase risk for incident myocardial infarction in depressed and nondepressed Veterans Administration patients. Am Heart J 2010;159:772-9.

45 Dinan TG. Inflammatory markers in depression. Curr Opin Psychiatry 2009;22:32.

46 Yasuda N, Mino Y, Koda S, Ohara $\mathrm{H}$. The differential influence of distinct clusters of psychiatric symptoms, as assessed by the general health questionnaire, on cause of death in older persons living in a rural community of Japan. J Am Geriatr Soc 2002;50:313-20.

47 Hamer M, David Batty G, Seldenrijk A, Kivimaki M. Antidepressant medication use and future risk of cardiovascular disease: the Scottish Health Survey. Eur Heart $J$ 2011;32:437-42. 
48 Alonso J, Angermeyer M, Bernert S, Bruffaerts R, Brugha T, Bryson H, et al. Psychotropic drug utilization in Europe: results from the European Study of the Epidemiology of Menta Disorders (ESEMeD) project. Acta Psychiat Scand 2004;109:55-64.

49 Harris EC, Barraclough B. Excess mortality of mental disorder. Br J Psychiatry 1998;173:11-53.

50 Hamer M, Stamatakis E, Steptoe A. Psychiatric hospital admissions, behavioral risk factors, and all-cause mortality: the Scottish Health Survey. Arch Intern Med 2008;168:2474-9.

51 Berkman L, Carney R, Blumenthal J, Czakowski S, Hosking J, Jaffe A. Enhancing recovery in coronary heart disease patients (ENRICHD): study design and methods. Am Heart $J$ 2000;139:1-9.

52 Berkman LF, Blumenthal J, Burg M, Carney RM, Catellier D, Cowan MJ, et al. Effects of treating depression and low perceived social support on clinical events after myocardial infarction: the Enhancing Recovery in Coronary Heart Disease Patients (ENRICHD) randomized trial. JAMA 2003;289:3106-16.
53 Glassman AH, O'Connor CM, Califf RM, Swedberg K, Schwartz P, Bigger JT, et al. Sertraline treatment of major depression in patients with acute MI or unstable angina. JAMA 2002;288:701-9.

\section{Accepted: 04 July 2012}

Cite this as: BMJ 2012;345:e4933

This is an open-access article distributed under the terms of the Creative Commons Attribution Non-commercial License, which permits use, distribution, and reproduction in any medium, provided the original work is properly cited, the use is non commercial and is otherwise in compliance with the license. See: http://creativecommons.org/licenses/bync/2.0/ and http://creativecommons.org/licenses/by-nc/2.0/legalcode. 


\section{Tables}

\begin{tabular}{|c|c|c|c|c|c|c|c|c|c|c|c|}
\hline \multicolumn{12}{|c|}{ Table 1| Characteristics of participants* according to individual cohort studies } \\
\hline & \multicolumn{11}{|c|}{ Year } \\
\hline & 1994 & 1995 & 1997 & 1998 & 1999 & 2000 & 2001 & 2002 & 2003 & 2004 & Overall \\
\hline $\begin{array}{l}\text { Household } \\
\text { response (\%) }\end{array}$ & 77 & 78 & 76 & 74 & 76 & 75 & 74 & 74 & 73 & 72 & - \\
\hline $\begin{array}{l}\text { Estimated adult } \\
\text { interview response } \\
(\%)\end{array}$ & 71 & 73 & 71 & 69 & 70 & 68 & 67 & 67 & 66 & 66 & - \\
\hline No of participants & 10599 & 10905 & 5875 & 11058 & 5522 & 8684 & 11283 & 5399 & 10887 & 5049 & 85261 \\
\hline \multicolumn{12}{|l|}{ Age (years) } \\
\hline Mean (SD) & $56.1(14.4)$ & $56.2(14.3)$ & $55.6(14.0)$ & $56.1(14.3)$ & $55.7(14.3)$ & $65.8(18.5)$ & $56.0(14.3)$ & $55.4(14.4)$ & $56.3(14.3)$ & $57.0(14.3)$ & $56.9(15.0)$ \\
\hline Range & $35-97$ & $35-100$ & $35-95$ & $35-97$ & $35-96$ & $35-107$ & $35-97$ & $35-97$ & $35-97$ & $35-96$ & $35-107$ \\
\hline Female & $5824(54.9)$ & $5897(54.1)$ & 3208 (54.6) & $6079(55.0)$ & $2998(54.3)$ & $5389(62.1)$ & $6267(55.5)$ & $3041(56.3)$ & $6056(55.6)$ & $2910(57.6)$ & $\begin{array}{c}47669 \\
(55.9) \\
\end{array}$ \\
\hline $\begin{array}{l}\text { Non-manual } \\
\text { occupational social } \\
\text { class } †\end{array}$ & 5555 (53.5) & $5880(55.1)$ & $3125(54.3)$ & $5865(54.3)$ & $3030(56.1)$ & $3548(55.7)$ & $6191(56.3)$ & $3034(57.7)$ & $6090(57.4)$ & $2925(59.5)$ & $\begin{array}{l}45243 \\
(55.8)\end{array}$ \\
\hline Current smoker & 2494 (23.5) & 2528 (23.2) & 1369 (23.3) & $2564(23.2)$ & 1245 (22.6) & $1428(17.7)$ & $2431(21.6)$ & $1215(22.5)$ & 2305 & $971(19.3)$ & $\begin{array}{l}18550 \\
(22.0)\end{array}$ \\
\hline $\begin{array}{l}\text { Drinks more than } \\
\text { recommended } \\
\text { alcohol limitł }\end{array}$ & $1992(18.8)$ & $2132(19.6)$ & $1175(20.1)$ & $2354(21.3)$ & $1053(19.2)$ & $1134(16.5)$ & $2391(21.2)$ & 1109 (20.6) & $-\S$ & $-\S$ & $\begin{array}{l}13340 \\
(19.8)\end{array}$ \\
\hline $\begin{array}{l}\text { Cardiovascular } \\
\text { disease } \boldsymbol{f}^{\text {at }} \\
\text { baseline }\end{array}$ & $506(4.8)$ & $547(5.0)$ & $265(4.5)$ & $500(4.5)$ & $271(4.9)$ & $661(7.6)$ & $566(5.0)$ & $225(4.2)$ & $482(4.4)$ & $226(4.5)$ & $4249(5.0)$ \\
\hline $\begin{array}{l}\text { Diabetes, including } \\
\text { hyperglycaemia, at } \\
\text { baseline }\end{array}$ & $277(2.6)$ & $324(3.0)$ & $203(3.5)$ & $335(3.0)$ & $206(3.7)$ & $405(4.7)$ & $483(4.3)$ & $221(4.1)$ & $517(4.7)$ & $277(5.5)$ & 3248 (3.8) \\
\hline $\begin{array}{l}\text { GHQ-12 score } \\
\text { (mean (SD)) }\end{array}$ & $1.5(2.6)$ & $1.7(2.8)$ & $1.5(2.7)$ & $1.5(2.7)$ & $1.7(2.8)$ & $1.6(2.8)$ & $1.3(2.5)$ & $1.6(2.7)$ & $1.3(2.5)$ & $1.3(2.6)$ & $1.5(2.7)$ \\
\hline $\begin{array}{l}\text { Consented to } \\
\text { mortality linkage }\end{array}$ & $\begin{array}{l}10095 \\
(95.2)\end{array}$ & $\begin{array}{l}10199 \\
(93.5)\end{array}$ & $5529(94.1)$ & $\begin{array}{l}10454 \\
(94.5)\end{array}$ & $5177(93.8)$ & $5926(68.2)$ & $9972(88.4)$ & $4774(88.4)$ & $9494(87.2)$ & 4316 (85.5) & $\begin{array}{l}75936 \\
(89.1)\end{array}$ \\
\hline $\begin{array}{l}\text { Follow-up (years, } \\
\text { mean (SD)) }\end{array}$ & $12.3(3.2)$ & $11.5(2.8)$ & $9.9(2.1)$ & $9.0(1.8)$ & $8.1(1.6)$ & $6.8(1.9)$ & $6.4(1.0)$ & $5.4(0.8)$ & $4.5(0.6)$ & $3.5(0.4)$ & $8.2(3.5)$ \\
\hline $\begin{array}{l}\text { Deaths from any } \\
\text { cause (no) }\end{array}$ & 1873 & 1764 & 700 & 1206 & 520 & 987 & 630 & 250 & 335 & 100 & 8365 \\
\hline $\begin{array}{l}\text { Cardiovascular } \\
\text { disease deaths } \\
(\mathrm{no})^{\star \star}\end{array}$ & 795 & 719 & 270 & 480 & 209 & 391 & 241 & 109 & 125 & 43 & 3382 \\
\hline $\begin{array}{l}\text { Total cancer deaths } \\
\text { (no) }\end{array}$ & 557 & 574 & 217 & 401 & 176 & 194 & 211 & 86 & 106 & 30 & 2552 \\
\hline $\begin{array}{l}\text { Deaths from } \\
\text { external causes } \\
\text { (no) }\end{array}$ & 68 & 68 & 29 & 64 & 19 & 47 & 44 & 19 & 23 & 5 & 386 \\
\hline
\end{tabular}

Data are no (\%) of participants unless stated otherwise. Any discrepancies in percentages are due to missing data. SD=standard deviation.

*Table represents all participants in the surveys, irrespective of consent to mortality linkage. All subsequent tables and figures represent only participants who consented to linkage and were therefore included in the present study.

†Non-manual occupational social class comprises professional, managerial or technical, and skilled non-manual classes (I-IIINM) according to the Registrar General classification.

¥Calculated using sex specific safe limits: $\leq 14$ units per week for women and $\leq 21$ units per week for men.

$\S$ In 2003 and 2004, alcohol intake was recorded in a different format to other years in the Health Surveys for England.

IIncluding angina, myocardial infarction, and haemorrhagic or thrombotic stroke.

**Total deaths caused by cardiovascular disease, comprising ischaemic heart disease, cerebrovascular disease, peripheral vascular disease, and heart failure. 


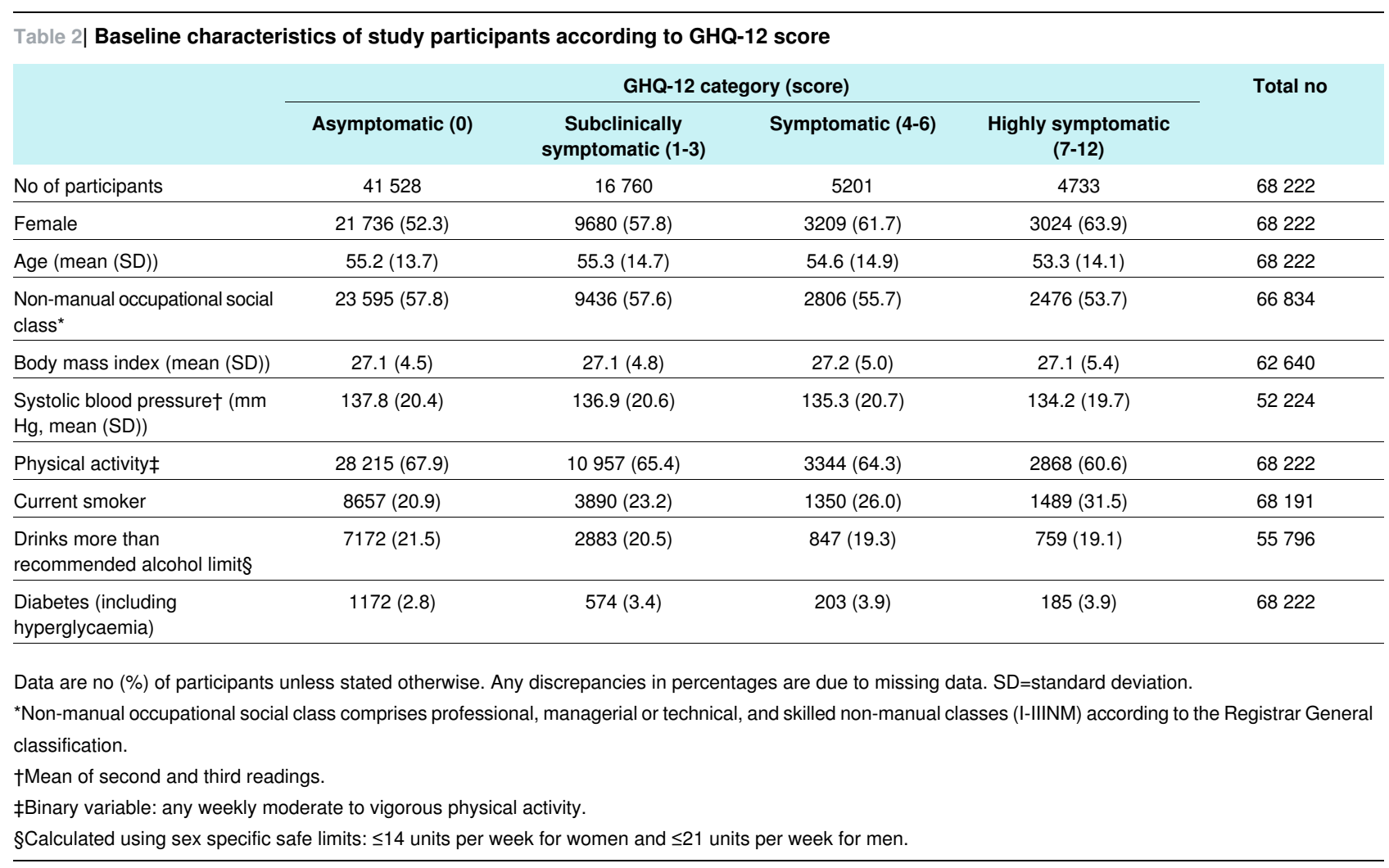




\begin{tabular}{|c|c|c|c|c|c|c|c|c|}
\hline \multirow[t]{2}{*}{ Model } & \multirow{2}{*}{$\begin{array}{c}\text { Deaths } \\
\text { (no) }\end{array}$} & \multirow{2}{*}{$\begin{array}{c}\text { Participants } \\
\text { (no) }\end{array}$} & \multicolumn{4}{|c|}{ GHQ-12 score } & \multirow{2}{*}{$\begin{array}{c}1 \text { standard } \\
\text { deviation } \\
\text { disadvantage in } \\
\text { GHQ-12 score }\end{array}$} & \multirow[t]{2}{*}{$\mathrm{P}$ for trenc } \\
\hline & & & 0 & $1-3$ & 4-6 & $7-12$ & & \\
\hline \multicolumn{9}{|l|}{ Total mortality } \\
\hline $\begin{array}{l}\text { Age and sex } \\
\text { adjusted }\end{array}$ & 8365 & 68222 & 1 (reference) & 1.20 (1.13 to 1.27$)$ & 1.43 (1.31 to 1.56$)$ & 1.94 (1.66 to 2.26$)$ & $1.21(1.15$ to 1.27$)$ & $<0.001$ \\
\hline Fully adjusted $\dagger$ & 4963 & 41362 & 1 & $1.16(1.08$ to 1.24$)$ & $1.37(1.23$ to 1.51$)$ & $1.67(1.41$ to 2.00$)$ & $1.16(1.12$ to 1.20$)$ & $<0.001$ \\
\hline \multicolumn{9}{|c|}{ Cardiovascular disease $\neq$ mortality } \\
\hline $\begin{array}{l}\text { Age and sex } \\
\text { adjusted }\end{array}$ & 3382 & 68222 & 1 (reference) & 1.29 (1.17 to 1.43$)$ & 1.44 (1.27 to 1.62$)$ & 2.05 (1.57 to 2.70$)$ & $1.22(1.14$ to 1.31$)$ & $<0.001$ \\
\hline Fully adjusted $†$ & 1956 & 41362 & 1 & 1.25 (1.08 to 1.44$)$ & $1.45(1.23$ to 1.71$)$ & $1.72(1.44$ to 2.06$)$ & 1.17 (1.12 to 1.22$)$ & $<0.001$ \\
\hline \multicolumn{9}{|c|}{ Cancer mortality } \\
\hline $\begin{array}{l}\text { Age and sex } \\
\text { adjusted }\end{array}$ & 2552 & 68222 & 1 (reference) & $0.92(0.84$ to 1.01$)$ & 1.07 (0.89 to 1.29$)$ & $1.41(1.22$ to 1.64$)$ & 1.09 (1.04 to 1.13$)$ & $<0.001$ \\
\hline Fully adjusted $†$ & 1698 & 41362 & 1 & 0.95 (0.85 to 1.07$)$ & $1.05(0.85$ to 1.30$)$ & $1.29(1.04$ to 1.61$)$ & $1.05(0.99$ to 1.11$)$ & 0.141 \\
\hline \multicolumn{9}{|c|}{ External cause mortality } \\
\hline $\begin{array}{l}\text { Age and sex } \\
\text { adjusted }\end{array}$ & 386 & 68222 & 1 (reference) & 1.29 (1.01 to 1.65$)$ & 1.93 (1.31 to 2.83$)$ & $2.34(1.52$ to 3.60$)$ & $1.26(1.14$ to 1.40$)$ & $<0.001$ \\
\hline Fully adjusted $\dagger$ & 241 & 41362 & 1 & $1.23(0.90$ to 1.70$)$ & $2.07(1.33$ to 3.21$)$ & $3.19(1.78$ to 5.70$)$ & $1.32(1.13$ to 1.55$)$ & 0.001 \\
\hline
\end{tabular}

Data are hazard ratio (95\% confidence interval) unless indicated otherwise.

*GHQ-12 score standardised with sex specific standard deviations.

†Model adjusted for age, sex, occupational social class, diabetes, body mass index, systolic blood pressure, physical activity, smoking, and alcohol consumption. $\ddagger$ Cardiovascular disease comprises ischaemic heart disease, stroke, peripheral vascular disease, and heart failure. 
Table 4 | Sensitivity analysis of association between psychological distress and cause specific mortality, with and without multiple imputation

\begin{tabular}{|c|c|c|c|c|c|c|}
\hline \multirow[b]{2}{*}{$\begin{array}{l}\text { Fully adjusted } \\
\text { model }^{\star} \text { by cause } \\
\text { of death }\end{array}$} & \multicolumn{3}{|c|}{ Meta-analysis } & \multicolumn{3}{|c|}{ Multiple imputation } \\
\hline & Deaths (no) & Participants (no) & $\begin{array}{l}1 \text { standard deviation } \\
\text { disadvantage in } \\
\text { GHQ-12 score† }\end{array}$ & Deaths (no) & Participants (no)‡ & $\begin{array}{l}1 \text { standard deviation } \\
\text { disadvantage in } \\
\text { GHQ-12 score }\end{array}$ \\
\hline Total & 4963 & 41362 & $1.16(1.12$ to 1.20$)$ & 8492 & 57861 & 1.15 (1.13 to 1.18$)$ \\
\hline $\begin{array}{l}\text { Cardiovascular } \\
\text { disease§ }\end{array}$ & 1956 & 41362 & 1.17 (1.12 to 1.22$)$ & 3440 & 57861 & $1.14(1.10$ to 1.19$)$ \\
\hline Cancer & 1698 & 41362 & 0.95 (0.85 to 1.07$)$ & 2530 & 57861 & 1.05 (1.01 to 1.09$)$ \\
\hline External cause & 241 & 41362 & 1.32 (1.13 to 1.55$)$ & 381 & 57861 & 1.23 (1.11 to 1.36$)$ \\
\hline
\end{tabular}

Data are hazard ratio (95\% confidence interval) unless indicated otherwise.

*Model adjusted for age, sex, occupational social class, diabetes, body mass index, systolic blood pressure, physical activity, smoking, and alcohol consumption. †GHQ-12 score standardised with sex specific standard deviations.

$\ddagger$ Total no of participants in multiple imputation models excludes the 2003 and 2004 cohort studies since they were excluded from all fully adjusted models owing to their recording of alcohol consumption in a different format to other years.

$\S$ Cardiovascular disease comprises ischaemic heart disease, stroke, peripheral vascular disease, and heart failure. 


\section{Figures}

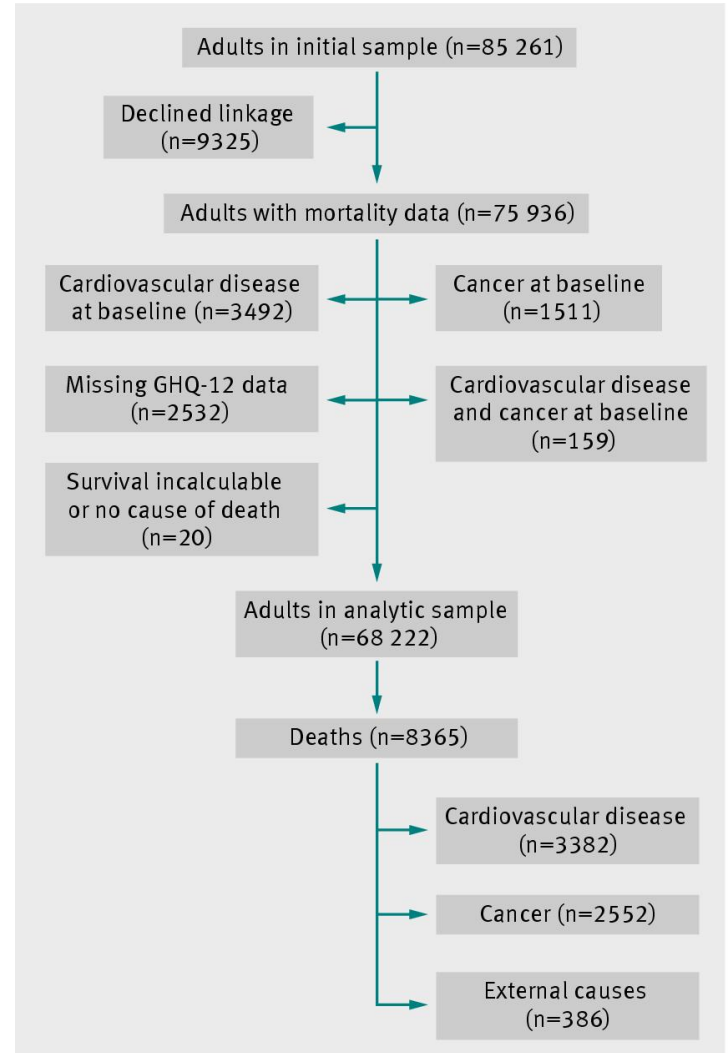

Fig 1 Flow chart of participants from initial pooled sample to analytic sample showing subsequent mortality 


\section{Overall death}

$\begin{array}{lccc}\text { Year } & \begin{array}{c}\text { Participants } \\ \text { (no) }\end{array} & \begin{array}{c}\text { Deaths } \\ \text { (no) }\end{array} & \begin{array}{c}\text { Hazard ratio } \\ (\mathbf{9 5} \text { ( Cl) }\end{array} \\ 1994 & 9183 & 1873 & 1.16(1.11 \text { to } 1.22) \\ 1995 & 9328 & 1764 & 1.13(1.08 \text { to } 1.18) \\ 1997 & 4963 & 700 & 1.12(1.04 \text { to } 1.20) \\ 1998 & 9335 & 1206 & 1.23(1.17 \text { to } 1.29) \\ 1999 & 4657 & 520 & 1.21(1.13 \text { to } 1.30) \\ 2000 & 5144 & 987 & 1.19(1.13 \text { to } 1.26) \\ 2001 & 8940 & 630 & 1.23(1.14 \text { to } 1.32) \\ 2002 & 4295 & 250 & 1.12(0.99 \text { to } 1.26) \\ 2003 & 8519 & 335 & 1.40(1.29 \text { to } 1.53) \\ 2004 & 3858 & 100 & 1.50(1.29 \text { to } 1.73) \\ \text { Overall } & \mathbf{6 8 2 2 2} & \mathbf{8 3 6 5} & \mathbf{1 . 2 1}(\mathbf{1 . 1 5} \text { to } 1.27)\end{array}$

Cancer death

Year Participants (no)

$1994 \quad 9183$

1995

1997

1998

1999

2000

2001

2002

2003

2004

Overall

\begin{tabular}{|c|c|c|}
\hline $\begin{array}{l}\text { articipants } \\
\text { (no) }\end{array}$ & $\begin{array}{c}\text { Deaths } \\
\text { (no) }\end{array}$ & $\begin{array}{c}\text { Hazard ratio } \\
(95 \% \mathrm{Cl})\end{array}$ \\
\hline 9183 & 557 & 1.06 (0.97 to 1.16$)$ \\
\hline 9328 & 574 & 1.00 (0.92 to 1.09$)$ \\
\hline 4963 & 217 & $1.10(0.97$ to 1.25$)$ \\
\hline 9335 & 401 & 1.13 (1.03 to 1.24$)$ \\
\hline 4657 & 176 & 1.10 (0.96 to 1.26$)$ \\
\hline 5144 & 194 & 1.12 (0.98 to 1.27$)$ \\
\hline 8940 & 211 & 1.11 (0.96 to 1.27$)$ \\
\hline 4295 & 86 & 0.97 (0.76 to 1.23$)$ \\
\hline 8519 & 106 & 1.19 (1.00 to 1.43$)$ \\
\hline 3858 & 30 & 1.42 (1.09 to 1.86$)$ \\
\hline 68222 & 2552 & $1.09(1.04$ to 1.13$)$ \\
\hline
\end{tabular}
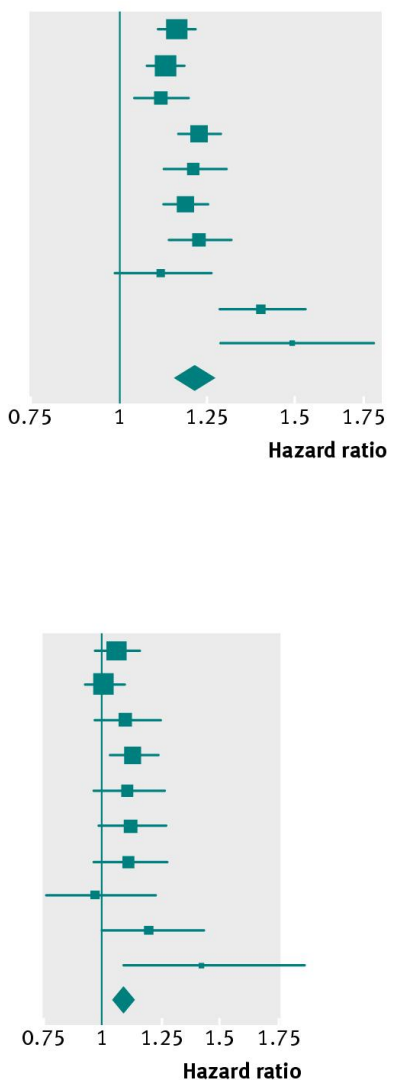

Cardiovascular disease death

$\begin{array}{cc}\begin{array}{c}\text { Deaths } \\ \text { (no) }\end{array} & \text { Hazard ratio } \\ & (95 \% \mathrm{Cl})\end{array}$

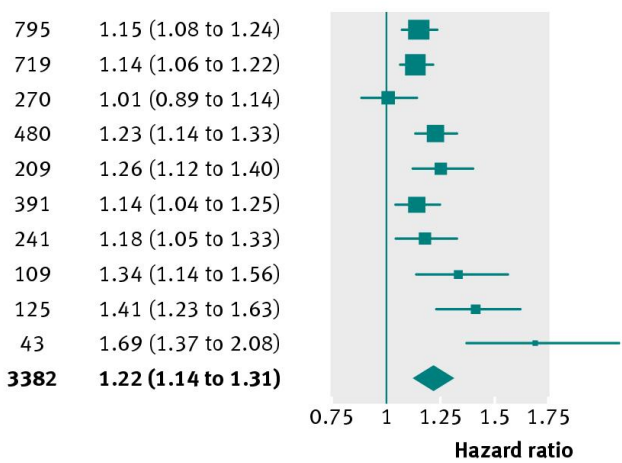

Deaths from external causes
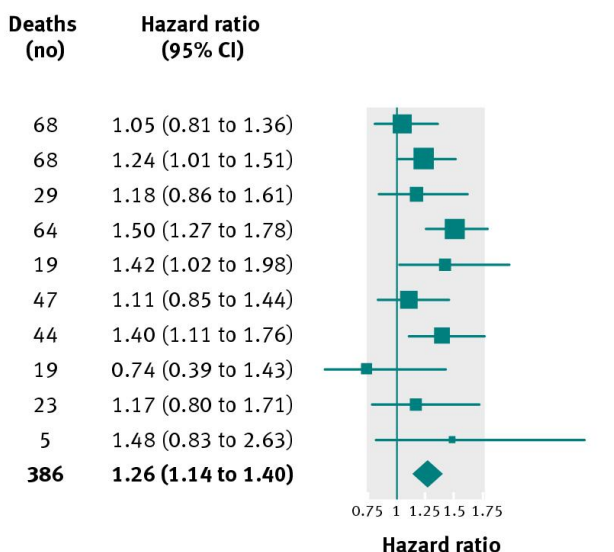

Fig 2 Number of participants, total mortality, and deaths plus age and sex adjusted hazard ratios (95\% confidence intervals) per standard deviation disadvantage in GHQ-12 score, by survey year and cause of death 

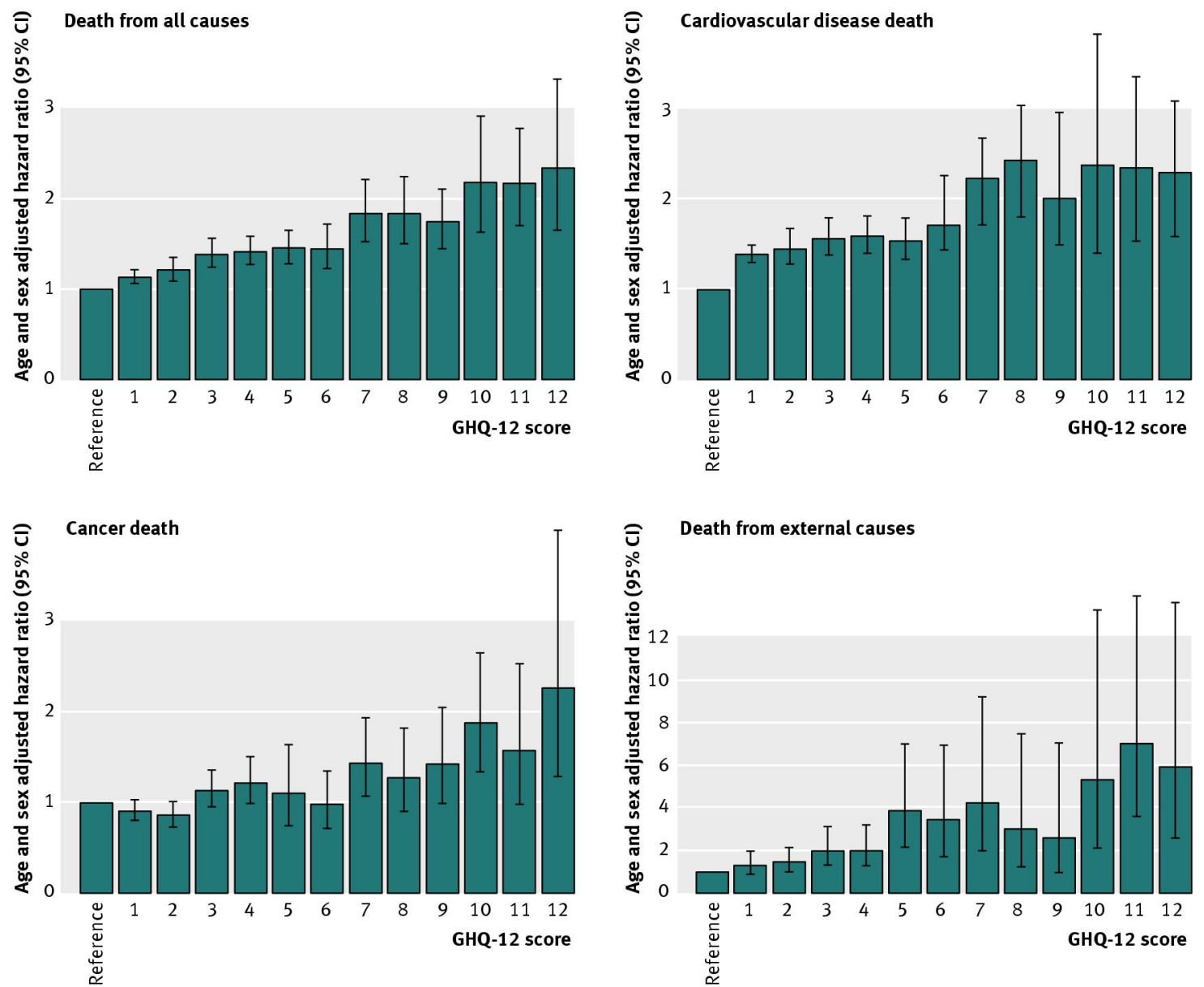

Fig 3 Association between psychological distress (GHQ-12 score) and risk of cause specific death (age and sex adjusted hazard ratio (95\% confidence interval)). Reference=GHQ-12 score 0; higher GHQ-12 score indicates greater distress 